\title{
A análise de risco como ferramenta estratégica para o serviço veterinário oficial brasileiro: dificuldades e desafios ${ }^{1}$
}

\author{
Diego V. Santos ${ }^{2,5 *}$, Bernardo Todeschini ${ }^{3}$, Christiane M.B.M. Rocha ${ }^{4}$ \\ e Luís G. Corbellini ${ }^{5}$
}

\begin{abstract}
Santos D.V., Todeschini B., Rocha C.M.B.M. \& Corbellini L.G. 2014. [Risk analysis as a strategic tool for Brazilian official veterinary service: problems and challenges.] A análise de risco como ferramenta estratégica para o serviço veterinário oficial brasileiro: dificuldades e desafios. Pesquisa Veterinária Brasileira 34(6):542-554. Seção de Epidemiologia e Estatística, Departamento de Defesa Agropecuária, Secretaria da Agricultura, Pecuária e Agronegócio do Rio Grande do Sul, Av. Getúlio Vargas 1384, Bairro Menino Deus, Porto Alegre, RS 90150-900, Brazil. E-mail: diego-santos@agricultura.rs.gov.br

The official veterinary service is responsible for protecting public and animal health, certifying the supply of safe animal products to consumers. A tool that assists in the pursuit of these goals is the risk analysis, which began to be used in the second half of the 1990s for the official veterinary services of countries. To carry out a risk analysis, qualitative or quantitative, one must initially identify the danger, which in the area of animal health is usually the pathogen causing a disease. The subsequent step is risk assessment, which must be analyzed, supported by scientific studies or experts in the field, the possible ways of introduction, exposition and maintenance of the pathogen in the susceptible population, as well biological, economic, political and social consequences. The third step in the analysis of risk refers to risk management, which aims to propose measures to mitigate the risk to the desired level, and assess the cost/benefit of each measure. The last phase of a risk analysis is risk communication. This step is critical for success of the study and should be initiated along with risk analysis itself, always leaving open a permanent communication with all social actors interested in risk analysis. Risk analysis has become an important tool used by managers of the official veterinary services in decision-making, contributing to the choice of alternatives that give scientifically the lowest animal health risk. This study conducted a review of the literature on risk analysis aimed to expose its definition and development process, as well as to see how it is being used and what limitations and challenges of using this tool by the Brazilian national veterinary service.
\end{abstract}

INDEX TERMS: SPS, World Trade Organization, WTO, OIE, risk assessment.

RESUMO.- O serviço veterinário oficial é responsável por proteger a saúde pública e animal, assegurando a oferta de produtos de origem animal inócuos aos consumidores. Uma ferramenta que auxilia na busca desses objetivos é a análise de risco, que iniciou a ser utilizada na segunda me-

\footnotetext{
${ }^{1}$ Recebido em 3 de fevereiro de 2014.

Aceito para publicação em 7 de maio de 2014.

${ }^{2}$ Seção de Epidemiologia e Estatística (SEE), Departamento de Defesa Agropecuária (DDA), Secretaria da Agricultura, Pecuária e Agronegócio do Rio Grande do Sul (SEAPA-RS), Av. Getúlio Vargas 1384, Bairro Menino Deus, Porto Alegre, RS 90150-900, Brasil. *Autor para correspondência: diego-santos@agricultura.rs.gov.br

${ }^{3}$ Divisão de Defesa Agropecuária, Superintendência Federal do Rio Grande do Sul, Ministério da Agricultura, Pecuária e Abastecimento (SFA-
}

tade da década de 90 pelos serviços veterinários oficiais dos países. Para a realização de uma análise de risco, qualitativa ou quantitativa, inicialmente deve-se identificar o perigo, a qual na área da saúde animal geralmente é o agente patogênico causador de uma doença. A etapa subsequente

\footnotetext{
-RS/ MAPA), Av. Loureiro da Silva 515/711, Porto Alegre, RS 90010-420. E-mail: bernardo.todeschini@agricultura.gov.br

${ }^{4}$ Setor de Medicina Veterinária Preventiva, Departamento de Medicina Veterinária (DMV), Universidade Federal de Lavras (UFLA), Cx. Postal 3037, Campus Universitário, Lavras, MG 37200-000, Brasil. E-mail: rochac@dmv.ufla.br

${ }^{5}$ Laboratório de Epidemiologia Veterinária (EPILAB), Dpto Medicina Veterinária Preventiva, Faculdade de Medicina Veterinária (FAVET), Universidade Federal do Rio Grande do Sul (UFRGS), Av. Bento Gonçalves 9090, Agronomia, Porto Alegre, RS 91540-000, Brasil. E-mail: luis.corbellini@ufrgs.br
} 
é a avaliação do risco, na qual devem ser analisados, com suporte de trabalhos científicos ou especialistas na área, as formas possíveis de introdução, exposição e manutenção do agente patogênico na população susceptível, bem como as consequências, biológicas, econômicas, políticas e sociais trazidas pela enfermidade. A terceira etapa da análise de risco refere-se ao manejo dos riscos, que visa propor medidas que mitiguem o risco verificado até o nível desejado, bem como avaliar o custo/benefício de cada medida. A última fase de uma análise de risco é a comunicação dos riscos. Essa etapa é fundamental para o sucesso do estudo e deve ser iniciada juntamente com a análise de risco em si, sempre deixando aberto um canal permanente de comunicação com todos os atores sociais interessados na análise de risco. A análise de risco tornou-se um importante instrumento utilizado pelos gestores dos serviços veterinários oficiais na tomada de decisões, contribuindo para a escolha de alternativas que confiram, cientificamente, o menor risco sanitário. Este trabalho realizou uma revisão da literatura sobre análise de risco objetivando expor sua definição e processo de elaboração, assim como verificar como ela está sendo utilizada, quais limitações e desafios do uso dessa ferramenta pelo serviço veterinário oficial brasileiro.

TERMOS DE INDEXAÇÃO: Acordo SPS, Organização Mundial do Comércio, OMC, OIE, avaliação de risco.

\section{INTRODUÇÃO}

O Serviço Veterinário Oficial (SVO) é responsável pela proteção e melhoria da saúde pública e animal. Sua principal tarefa é garantir que todas as partes envolvidas na produção de alimentos cumpram com suas respectivas obrigações sanitárias e higiênicas, a fim de assegurar um alimento seguro para o consumidor (Marabelli 2003). No Brasil, o SVO é representado, em nível federal, pelo Ministério da Agricultura, Pecuária e Abastecimento (MAPA) e pelo Ministério da Pesca e Aquicultura (MPA) e, em nível estadual, pelos órgãos de defesa sanitária animal das unidades federativas.

Desde a criação do Acordo sobre a aplicação de medidas sanitárias e fitossanitárias (SPS) (WHO 1995) pela Organização Mundial do Comércio (OMC), o SVO ganhou ainda mais importância. Apesar de algumas críticas (Silverglade 2000), tal acordo estabeleceu regras para regulamentar o comércio internacional de animais e produtos de origem animal e vegetal, a fim de evitar a imposição, por parte do país importador, de barreiras não tarifarias, na forma de medidas sanitárias injustificadas com finalidade de proteger sua indústria nacional da competição de produtos importados (Vallat \& Wilson 2003, OIE 2006). 0 acordo SPS especifica regulamentações básicas sobre segurança dos alimentos e Standards em saúde animal e vegetal e parte da premissa de que as medidas de proteção à saúde animal, humana e vegetal devam ser baseadas em princípios científicos, não sendo aplicadas de forma discriminatória ou de forma a constituir restrição velada ao comércio internacional.

A partir do acordo SPS, a OMC definiu, em 1998, a Organização Mundial de Saúde Animal (OIE) como a orga- nização normatizadora responsável pelo estabelecimento dos padrões e recomendações internacionais quanto às medidas sanitárias necessárias para o comércio de animais e seus produtos (Brückner 2009, OIE 2013b). Da mesma forma, o "Codex Alimentarius Comission" (CAC) é uma comissão criada pela Organização Mundial da Saúde (OMS) e Organização Mundial das Nações Unidas para a Agricultura e Alimentação (FAO) que, através da elaboração de manuais e códigos de boas práticas, é referência internacional associada ao desenvolvimento de Standards em alimentos (WHO/FAO 2005). Desde então, países membros da OMC deveriam justificar as medidas sanitárias impostas para a importação de animais e seus produtos, utilizando preferencialmente aquelas baseadas nas recomendações preconizadas pela OIE (Thiermann 2005, OIE 2012a, 2012b). No caso de ausência de recomendações ou da adoção de medidas mais restritivas do que aquelas recomendadas pela OIE, o próprio país importador deve basear as medidas sanitárias adotadas em análises de risco específicas, conforme o modelo proposto por Covello \& Merkhoher (1993) e preconizado pela OIE (MacDiarmid \& Pharo 2003, Dufour et al. 2011). Portanto, a Análise de Risco (AR) no âmbito do comércio de animais e seus produtos visa facilitar o comércio internacional, ao mesmo tempo em que pretende proteger a saúde animal e humana (MacDiarmid \& Pharo 2003). Por outro lado, a adoção de códigos de boas práticas e aplicação da análise de risco na cadeia alimentar (CAC 1999, 2007, 2011) preconizados pelo CAC, em teoria, também serve como facilitador para o comércio internacional de alimentos de origem animal e vegetal, pois estas recomendações são referência global para os consumidores, produtores e indústria processadora de alimentos e agências nacionais de vigilância (Schaffner 2008). De forma mais ampla, a AR na veterinária poderia ser considerada uma ferramenta que auxilia na tomada de decisões, proporcionando a obtenção, mediante um processo lógico, estruturado e consistente, de informações sobre o risco de introdução, estabelecimento e difusão de doenças, estimando o seu impacto econômico e suas consequências para a saúde pública e animal (OIE 2006). No âmbito da segurança dos alimentos, a AR é um método que auxilia na promoção da saúde pública, uma vez que a forma estruturada de análise do processo de produção (da "fazenda à mesa") permite avaliar o impacto de medidas de mitigação na ocorrência de casos de doenças transmitidas pelos alimentos.

Os SVO utilizaram, de alguma forma, a AR para seus sistemas de vigilância, monitoria, controle e erradicação de doenças, ainda que essa utilização não seguisse uma forma estruturada (Zepeda et al. 2001, OIE 2006, Willeberg et al. 2012). 0 advento do acordo SPS fez com que AR estruturadas tenham sido realizadas pelo SVO e colaboradores, tanto de países importadores quanto exportadores, com objetivo de avaliar perigos aos quais populações animais e humanas poderiam ser expostas devido à circulação de animais e seus produtos.

A AR, no âmbito governamental, tem sido amplamente utilizada para avaliar os riscos de introdução de agentes patogênicos através da importação de produtos de origem animal e vegetal (Análise de Risco de Importação) bem 
como estimar, para uma população, a probabilidade de ocorrência de uma doença transmitida por um patógeno que pode estar presente no alimento de origem animal e as consequências associadas (Análise de Risco Microbiológica em alimentos). 0 presente trabalho está focado primariamente na análise qualitativa de risco de importação de produtos que possam conter um determinado patógeno, tendo como objetivo realizar uma revisão da literatura abordando aspectos sobre o que é, como se elabora e como a análise de risco está sendo utilizada pelo SVO brasileiro para proteger, manter e evoluir o status sanitário dos rebanhos, destacando suas dificuldades e desafios.

\section{REVISÃO DE LITERATURA}

A AR é uma importante ferramenta que facilita a tomada de decisão, sendo utilizada em diversas áreas do conhecimento, como por exemplo, na engenharia (Almeida 2005), medicina (Everett 1981), segurança dos alimentos (Schaffner 2008) e na medicina veterinária (Yu et al. 1997, Palmer et al. 2005, Armstrong \& Haas 2007, Corbellini et al. 2010, Sanchez-Vizcaino et al. 2010a, Corbellini et al. 2012, Willeberg et al. 2012). Um estudo de AR pelo SVO pode ser realizado para avaliar o potencial de ingresso de uma enfermidade e suas possíveis vias de introdução (Sanchez-Viscaino et al. 2010a, 2010b, Hasler et al. 2012), para estimar o risco que representa a importação de um produto especifico (Miller et al. 1993, OIE 2006) e avaliar o impacto de determinados pontos críticos do processo de produção na incidência de doenças transmitidas pelo alimento, contribuindo para gestão de riscos dos processos de produção de alimentos (Schaffner 2008, Pouillot et al. 2012).

A AR é uma ferramenta preconizada pela OIE para que os países membros interessados busquem um adequado nível de proteção para a sanidade de seus rebanhos nas relações de comércio internacional (Covello \& Merkhoher 1993). Utilizada há pouco mais de uma década na área da saúde animal, portanto podendo ser considerada uma técnica recente, o uso da AR disseminou-se rapidamente dentro dos SVO, em especial daqueles importadores de animais e seus produtos e hoje é utilizada rotineiramente para avaliação e mensuração de riscos oferecidos pela importação de produtos agropecuários. Outra característica importante da AR é seu caráter técnico e objetivo, que auxilia os gestores nas suas escolhas, já que ela tenta eliminar ou, pelo menos, reduzir a subjetividade na tomada de decisões (OIE 2006).

\section{Etapas de uma Análise de Risco}

A AR, conforme modelo adotado pela OIE, é composta de 4 etapas: (i) identificação dos perigos, (ii) avaliação dos riscos, (iii) manejo dos riscos e (iv) comunicação dos riscos.

\section{1) Identificação do perigo}

Perigo é definido como a fonte de um dano potencial, que poderá causar um evento adverso (OIE 2006). A identificação do perigo é o processo de identificar algum agente patogênico, físico ou químico, que poderia ser introduzido em um país ou região e que poderia trazer danos, sanitários ou econômicos à produção animal e saúde pública (Covello
\& Merkhoher 1993, Miller et al. 1993, MacDiarmid \& Pharo 2003, OIE 2006).

A identificação do perigo, quando este se tratar de um agente patogênico, passa pelo conhecimento das propriedades deste agente, assim como a epidemiologia da enfermidade causada pelo mesmo nas populações locais e globais. Essas informações devem ser buscadas na literatura científica, nos SVO dos países e junto a OIE, a qual disponibiliza informações das ocorrências sanitárias das enfermidades animais em seu site (OIE 2013a). Ressalta-se que é importante buscar informações em fontes confiáveis, podendo abranger bibliotecas, buscas na internet e consultas junto a especialistas na área (Miller et al. 1993, Moutou et al. 2001, Uhlenhopp 2002, MacDiarmid \& Pharo 2003, Hauser et al. 2004, OIE 2006). A fim de auxiliar na compilação das informações pesquisadas, pode ser realizado processo de revisão sistemática ou meta-análise para determinadas informações objetivando estruturar os dados existentes (Dohoo et al. 2010). Para cada produto a ser importado, o avaliador de risco deve identificar que agentes podem estar presentes, levando em consideração a situação epidemiológica da região e as características do produto. Por exemplo, a "Australian Quarantine and Inspection Services (AQIS)" identificou os seguintes perigos em uma análise de risco de importação de sêmen e embrião bovino da Argentina e Brasil: vírus da febre aftosa, vírus da estomatite vesicular, vírus da língua azul, Leptospira spp., vírus da raiva, Mycobacterium paratuberculosis, $M$. bovis, Brucella abortus, vírus da leucose bovina, Pasteurella multocida (sorotipos B:2 e E:2), Herpevírus bovino, Pestivírus bovino e o vírus da epizootia hemorrágica de cervos (AQIS 1999).

\section{2) Avaliação dos riscos}

A probabilidade da ocorrência de um evento adverso (foco de uma doença causada por um determinado perigo identificado na etapa anterior) e a magnitude de suas consequências é chamada de risco (Miller et al. 1993, OIE 2006). Portanto, conforme preconiza o Código Sanitário dos Animais Terrestres da OIE, depois de alcançada a identificação do perigo, deve ser realizada uma avaliação do risco (OIE 2012b). Desta forma, esta etapa de avaliação do risco consiste em avaliar a probabilidade de ocorrência e as consequências biológicas e econômicas da entrada, difusão e manutenção do perigo dentro de uma zona ou país (MacDiarmid 1993, MacDiarmid \& Pharo 2003, Murray et al. 2004, OIE 2006, 2012b). É importante destacar que o artigo $5^{\circ}$ do acordo SPS refere-se à avaliação de risco, enquanto a OIE descreve e recomenda a AR, onde a avaliação de risco é um dos componentes do processo (Zepeda et al. 2005).

\section{1) Tipos de avaliação de risco}

Quanto à mensuração dos riscos, a avaliação de risco pode ser classificada de duas formas: qualitativa ou quantitativa. No primeiro tipo de avaliação de risco, o resultado da avaliação das consequências é expresso em escalas descritivas, utilizando termos como "alto", "médio" ou "baixo". Já na avaliação de risco quantitativa, a probabilidade é expressa em valores numéricos, que oferece uma noção mais precisa da ocorrência de um evento adverso (MacDiarmid 
1993, MacDiarmid \& Pharo 2003, Murray et al. 2004, OIE 2006). Embora ambas as avaliações de risco sejam válidas, normalmente realiza-se primeiro uma avaliação de risco qualitativa (Pintelon 1994). O presente artigo se focará mais na estimação de riscos qualitativa, como explicado posteriormente e citará exemplos de aplicações de distribuição quantitativa aplicada em análises quantitativas.

2.1.1) Avaliação de risco qualitativa. Considerada como de execução mais simples e rápida, quando comparada com a avaliação de risco quantitativa. Nesse tipo de avaliação, não há a quantificação numérica de probabilidade das variáveis, sendo utilizadas escalas descritivas para avaliar a probabilidade da ocorrência de cada evento. Normalmente, essa avaliação qualitativa é utilizada como avaliação inicial para identificar situações que demandem um estudo mais profundo, em casos que o risco em questão não justifica o tempo e esforço requerido por uma análise mais detalhada ou, ainda, quando não há informações suficientes para quantificar os parâmetros das variáveis do modelo quanto à introdução ou ocorrência do perigo da análise (OIE 2006). No Brasil, a maioria das avaliações de risco na área de saúde animal realizadas até o momento é qualitativa (Quadro 1), justamente pela falta de informações para quantificar alguns parâmetros dos estudos (Figueiredo et al. 2012a, Figueiredo et al. 2012b, Cunha et al. 2012).

2.1.2) Avaliação de risco quantitativa. Em termos gerais, se prefere esse tipo de análise, pois há uma base mais sólida para a tomada de decisões, já que há uma mensuração numérica dos valores de probabilidade quanto aos riscos e medidas mitigatórias. Esse tipo de avaliação utiliza valores numéricos para estimar a probabilidade de ocorrência de cada evento. A dificuldade para a realização desse tipo de análise é a sua complexidade, a qual demanda um tempo maior quando comparado com a análise qualitativa, assim como a comum falta de informações quantitativas necessárias para mensurar cada evento da AR (Miller et al. 1993). No Brasil, em áreas onde o sistema de vigilância em saúde animal está mais bem estruturado e, portanto, possui os dados necessários para a realização desse tipo de análise, como é o caso da suinocultura industrial, há estudos desse tipo realizados (Salman et al. 2006, Delphino 2010). Na avaliação de risco quantitativa, a estocasticidade dos eventos é determinada através da aplicação de distribuições de probabilidades na qual, através de simulações de Monte Carlo, resultarão em um intervalo de probabilidade. Ou seja, ao contrário de uma análise determinística, cujo resultado é um valor fixo, os modelos estocásticos resultam em uma distribuição de probabilidade de um dado evento que são determinados, por sua vez, pelos valores aplicados aos parâmetros da distribuição. Por exemplo, até o momento o Brasil nunca registrou casos de PRRS (Porcine Reproductive and Respiratory Syndrome) (OIE 2013a). Neste panorama, o SVO poderia realizar uma AR caso houvesse uma demanda para importação de sêmen suíno de um determinado país. Ao identificar que PRRS pode estar presente no sêmen, é necessário obter informação acerca da detecção do agente no sêmen no país de origem e a quantidade importada, por exemplo, por mês, para avaliar a probabilidade de um frasco de sêmen suíno estar conta- minado com o vírus. Se a prevalência média de contaminação de sêmen suíno de um determinado país for de 0,02\% e, a cada mês, fosse importado em média 5000 frascos, a probabilidade de entrada de sêmen contaminado a cada mês poderia ser estimada através da distribuição binomial, pelos parâmetros de prevalência $(p)$ e número de frascos $(n)$. Neste caso, a média mensal de números de frascos contaminados seria dada por $n . p$, ou seja, 1 frasco. Aplicando-se estes valores a distribuição binomial (5.000; 0,02\%), se pode estimar a distribuição de probabilidade do número de frascos de sêmen contaminados. A Figura 1 ilustra esta distribuição após a simulação computacional utilizando 10 mil iterações no software @ risk. Com estes parâmetros, haveria uma probabilidade de $26.4 \%$ de cada lote conter pelo menos um frasco contaminado.

\section{2) Etapas para a avaliação de risco}

Segundo o Código Terrestre da OIE (OIE 2012b), esta etapa da análise de risco, tanto qualitativa como quantitativa, compreende quatro passos que fazem a avaliação da: 1) introdução (ou difusão); 2) exposição; 3) consequências e 4) estimação dos riscos, conforme descrito abaixo.

2.2.1) Avaliação da introdução. Essa fase descreve a probabilidade de introdução do perigo, desde o local de origem até o local de destino dos animais ou de seus produtos (OIE 2006, Figueiredo et al. 2012c). Consiste em descrever os processos biológicos necessários para que uma atividade de importação provoque a introdução de agentes patogênicos por um meio determinado e estimar a probabilidade que isso ocorra efetivamente (MacDiarmid 1993, Murray et al. 2004)

Para esta avaliação deve ser levado em consideração o volume esperado de transações de animais ou de seus produtos entre os países; a infraestrutura do SVO do país de origem; a distribuição e prevalência do agente no país ou na região de origem; as medidas preventivas adotadas pelo SVO no país de origem e sua eficiência; a sobrevivência do agente patogênico de interesse no animal ou produtos, levando em consideração as variáveis como espécie, raça, locais de predileção do agente e as condições de processamento; potencial de contaminação existente e ações e medidas preventivas adotadas no país de destino (MacDiarmid \& Pharo 2003, Marabelli 2003, Vallat \& Wilson 2003, Murray et al. 2004, OIE 2006, 2012b, Leanes et al. 2011).

2.2.2) Avaliação da exposição. Nessa fase, busca-se descrever os processos biológicos necessários para que os animais e as pessoas do país importador sejam expostos ao perigo introduzido a partir de uma fonte de risco determinada pelo país exportador (de origem) e estimar qualitativamente ou quantitativamente a probabilidade dessa exposição (Hauser et al. 2004, OIE 2006, 2012b, Paton et al. 2010, Mur et al. 2012).

Para isso, se faz necessário conhecer a distribuição das populações suscetíveis no país de destino; a proporção de indivíduos imunes nessas populações com relação ao agente patogênico em questão; a forma de utilização do produto ou animal no país de destino; o mecanismo de transmissão da enfermidade; fatores de risco que afetam a sobrevivência do organismo; a presença de vetores potenciais e o ciclo de vida 
do agente patogênico, identificando hospedeiros secundários ou intermediários (OIE 2006, Figueiredo et al. 2012c).

Tendo estabelecido as duas avaliações (de introdução e exposição), pode-se estimar da probabilidade de ocorrência da enfermidade no país de destino. A variação dos resultados de uma análise de risco quantitativa pode ser decorrente de incertezas e variabilidade dos parâmetros utilizados. Incerteza se constitui na falta de conhecimento sobre um determinado parâmetro e pode ser reduzida com a coleta de dados. A variabilidade, por sua vez, representa uma heterogeneidade que é inerente à população, não diminuindo com mais coleta de dados (Nauta, 2000). Ao se construir um modelo que descreva os caminhos de entrada e exposição de uma população a um determinado patógeno, como explicado anteriormente, se faz necessário a obtenção de uma série de dados que, muitas vezes, são escassos ou até mesmos indisponíveis. Nesta circunstância,

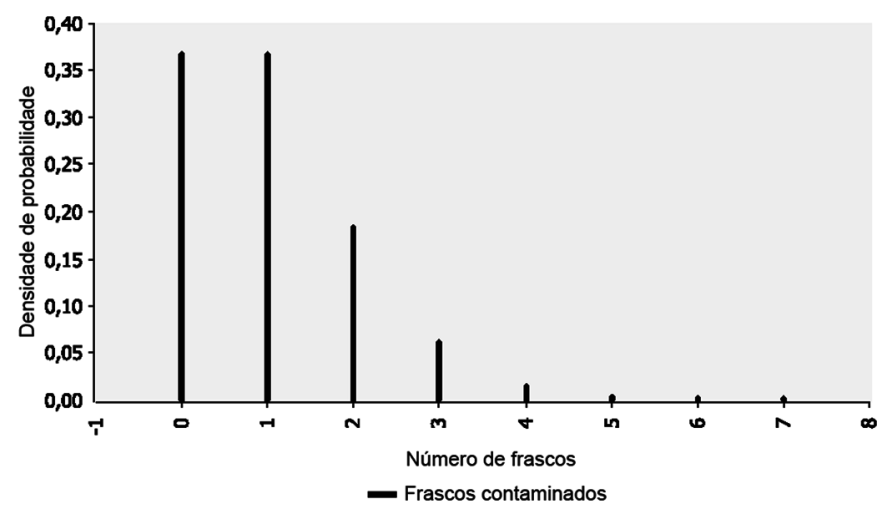

Fig.1. Exemplo de aplicação de distribuição de probabilidades comumente aplicada em análise de risco quantitativa numa situação hipotética de importação de 5.000 frascos de sêmen suíno por mês. Se no país de origem a prevalência média de PRRS no sêmen é de $0,02 \%$, haveria $90 \%$ probabilidade de cada lote conter entre 0 a 3 frascos contaminados por mês. 0 gráfico ilustra a distribuição de probabilidade binomial (5.000;0.02\%) depois de realizada simulação de Monte Carlo com 10.000 iterações. a estimativa de risco conterá um alto grau de incerteza. No caso de uma análise quantitativa de importação, muito dos parâmetros utilizados para caracterizar os riscos são obtidos através de dados escassos ou através da obtenção de informação de especialistas na área. Distribuições de probabilidades, como exemplificado na seção 2.1 .2 , são utilizadas para quantificar as incertezas na quantificação dos parâmetros. Para incorporar a incerteza no cálculo do risco, são utilizados modelos de simulação, com auxílio de softwares, que repetem o cálculo múltiplas vezes (cada cálculo é chamado de iteração) e que finalmente expressam valores de acordo com a distribuição de probabilidades que tenha sido determinada para cada parâmetro (MacDiarmid \& Pharo 2003, OIE 2006). Alguns softwares que realizam simulações de Monte Carlo são o @risk (Palisade) e ModelRisk (Vose Software), ambos comerciais e o R, software livre. Os dois primeiros são suplementos que rodam no Excel e o R exige conhecimento de sua linguagem específica. A Figura 1 ilustra as incertezas com relação a introdução de PRRS através da importação de sêmen contaminado.

Assim, a probabilidade de ocorrência (de um foco ou caso de doença numa população), definida como a análise conjunta da avaliação da introdução e da avaliação da exposição, pode ser obtida e categorizada, no caso da AR qualitativa, como insignificante (o evento não ocorreria), extremamente baixa (extremamente improvável que o evento ocorra), muito baixa (muito improvável que o evento ocorra), baixa (improvável que o evento ocorra), ligeira (possível que ocorra o evento em uma probabilidade baixa), moderada (possível que ocorra o evento em uma probabilidade alta) e alta (altamente provável que ocorra o evento) (OIE 2006). A matriz de categorização da probabilidade de ocorrência preconizada pela OIE pode ser visualizada na Figura 2. Há trabalhos que propõem outras classificações categóricas ordinais, mais específicas com até dez categorias (Dufour et al. 2011). Entretanto, comumente é utilizada a categorização proposta pela OIE.

2.2.3) Avaliação das consequências. Nessa etapa, realiza-se a descrição da relação entre determinadas condi-

\begin{tabular}{|c|c|c|c|c|c|c|c|c|}
\hline & & \multicolumn{7}{|c|}{ Probabilidade de introdução } \\
\hline & Categorização & Insignificante & \begin{tabular}{|c|}
$\begin{array}{c}\text { Extremamente } \\
\text { baixa }\end{array}$ \\
\end{tabular} & Muito baixa & Baixa & Ligeira & Moderada & Alta \\
\hline \multirow{7}{*}{ 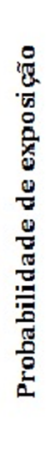 } & Alta & I & EB & MB & B & L & $\mathrm{M}$ & A \\
\hline & Moderada & I & EB & MB & B & $\mathrm{L}$ & M & M \\
\hline & Ligeira & I & $\mathbf{I}$ & EB & MB & B & $\mathbf{L}$ & $\mathrm{L}$ \\
\hline & Baixa & I & $\mathbf{I}$ & I & EB & MB & B & B \\
\hline & Muito Baixa & I & $\mathbf{I}$ & I & 1 & EB & MB & MB \\
\hline & $\begin{array}{c}\text { Extremamente } \\
\text { baixa }\end{array}$ & I & $\mathbf{I}$ & I & I & I & EB & EB \\
\hline & Insignificante & I & $\mathbf{I}$ & I & I & I & I & I \\
\hline
\end{tabular}

Fig.2. Matriz para a Categorização da Probabilidade de Ocorrência (adaptado de OIE 2006). 
ções de exposição a um perigo e as consequências dessa exposição. As consequências podem ser divididas em diretas e indiretas e podem ser agrupadas em biológicas, econômicas, sociais e políticas (Bier \& Mosleh 1990, MacDiarmid 1993, Pintelon 1994, MacDiarmid \& Pharo 2003, OIE 2006, Evans 2006, Cohen et al. 2007, Campbell 2008, WHO 2013).

Consequências biológicas são aquelas derivadas da introdução e exposição do agente patogênico dentro de uma população suscetível, levando em consideração a magnitude dos efeitos da ocorrência do agente em termos de morbidade, mortalidade e letalidade. Estas consequências devem ser mensuradas de acordo com as informações obtidas acerca da população, como a distribuição espacial de animais suscetíveis, características do agente, e fatores do meio ambiente, além da capacidade de detecção e de resposta rápida por parte do SVO devem ser consideradas (OIE 2006).

Consequências econômicas são aquelas relacionadas com o possível prejuízo de produção ou de exportação em caso de entrada, estabelecimento e propagação de uma doença. Outros aspectos como os custos de controle ou erradicação da enfermidade e a relação custo/benefício de outros métodos para mitigar o risco devem ser avaliados (Murray et al. 2004, OIE 2012b).

A avaliação das consequências pode ser categorizada em insignificantes (as consequências biológicas e econômicas derivadas da introdução do agente patogênico são insignificantes), muito baixas (as consequências biológicas e econômicas derivadas da introdução do agente patogênico são pequenas), baixas (as consequências biológicas e econômicas derivadas da introdução do agente patogênico são baixas), moderadas (as consequências biológicas e econômicas derivadas da introdução do agente patogênico são intermediárias), altas (as consequências biológicas e econômicas derivadas da introdução do agente patogênico são severas) e extremas (as consequências biológicas e econômicas derivadas da introdução do agente patogênico são catastróficas) (Murray et al. 2004, OIE 2012b).
2.2.4) Estimação do risco. Para realizar a estimação do risco, devem-se analisar os dados obtidos da avaliação de ocorrência (análise conjunta da probabilidade de introdução e exposição) e da avaliação das consequências da doença (OIE 2006, Figueiredo et al. 2012c). A matriz de categorização da estimação de risco preconizada pela OIE (OIE, 2006) pode ser visualizada na Figura 3.

Ressalta-se que a utilização de matrizes para determinar o risco numa AR possui suas limitações (Carr \& Tah 2001, Ni et al. 2010). Em modelos quantitativos ou semi-quantitativos, em especial se a probabilidade da ocorrência de um evento e a magnitude das consequências forem negativamente correlacionadas, podem acorrer erros de avaliação de risco e, consequentemente, escolhas de priorização de risco errôneas (Cox Jr. 2008, Markowski \& Mannan 2008). Outro problema do uso das matrizes é a subjetividade, sendo que diferentes pessoas podem fazer escolhas diferentes, pois podem haver graus de subjetividades ou variação nas variáveis analisadas, resultando em riscos diferentes conforme o avaliador (Cox Jr. 2008).

Assim, se faz necessário o uso com parcimônia das matrizes de risco, sendo que nem sempre as mesmas são um bom suporte para decisões de manejo de risco (Cox Jr. 2008, Markowski \& Mannan 2008).

Posteriormente, depois de finalizada a estimação do risco, é possível realizar uma análise de sensibilidade do modelo. $\mathrm{Na}$ análise quantitativa, tal procedimento visa verificar o comportamento do modelo em face da alteração de parâmetros utilizados para quantificar os riscos, ou ainda realizando uma avaliação estatística do peso de cada parâmetro no resultado final, através da análise de correlação, por exemplo. Nos modelos qualitativos, tal analise poderia ser conduzida pela intercambio de probabilidades na matriz de categorização de riscos, o que permitiria trabalhar com cenários de estimação qualitativa de risco. Assim, podem-se determinar quais são os pontos mais importantes na existência do risco e direcionar as medidas que visam

\begin{tabular}{|c|c|c|c|c|c|c|c|}
\hline & & \multicolumn{6}{|c|}{ Consequências* } \\
\hline & Categorização & Insignificantes & Muito baixas & Baixas & Moderadas & Altas & Extremas \\
\hline \multirow{7}{*}{ 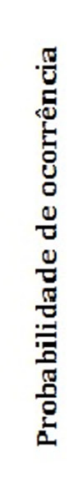 } & Alta & I & MB & B & M & A & $\mathrm{E}$ \\
\hline & Moderada & I & MB & B & M & A & $\mathrm{E}$ \\
\hline & Ligeira & I & MB & B & M & A & $\mathrm{E}$ \\
\hline & Baixa & I & I & $\mathrm{MB}$ & $\mathrm{B}$ & M & A \\
\hline & Muito Baixa & I & I & I & MB & B & M \\
\hline & $\begin{array}{c}\text { Extremamente } \\
\text { baixa }\end{array}$ & I & I & I & I & $\mathrm{MB}$ & $\mathrm{B}$ \\
\hline & Insignificante & I & I & I & I & I & MB \\
\hline
\end{tabular}

Fig.3. Matriz da Estimação do risco (adaptado de OIE 2006). 
mitigar esse risco de forma mais eficiente (Urbina-Amaris 2003, OIE 2006).

\section{3) Manejo do risco}

Processo de identificar, avaliar, selecionar e implantar medidas para mitigar a probabilidade de ocorrer um evento não desejado ou diminuir a magnitude das consequências atreladas à ocorrência do evento (Bier \& Mosleh 1990, Pintelon 1994, MacDiarmid \& Pharo 2003, Campbell 2008).

Inicialmente, se realiza a apreciação do risco, que consiste em comparar o resultado obtido com um nível de risco aceitável de proteção estabelecido por um país (MacDiarmid \& Pharo 2003).

O risco aceitável, segundo a OIE, é definido como o nível de risco arbitrado pelos países membros como compatível com a proteção animal e a saúde pública dentro de seus respectivos países (OIE 2012b). Entretanto, em negociações e transações internacionais de animais e seus produtos envolvendo países membros da OIE, não é tão fácil determinar o que é um risco aceitável, pois o que é aceitável para um grupo (país exportador) pode não ser aceitável para outro (país importador) (MacDiarmid 1993, Murray et al. 2004).

Ressalta-se que a determinação do risco aceitável é importante, pois após a avaliação do risco, com base no parâmetro de risco aceitável proposto, serão tomadas as medidas de manejo do risco que visem mitigá-lo até o nível de risco aceitável (tolerado) (MacDiarmid \& Pharo 2003).

\section{4) Comunicação do risco}

É a parte da AR que assegura a transparência mediante o estabelecimento de canais de comunicação com todos os atores envolvidos no processo (OIE 2006). Deve fazer parte do processo desde o início da AR e ocorrer ao longo de seu desenvolvimento, sendo assim um processo horizontal. A comunicação trata de informar as partes potencialmente afetadas e interessadas na AR quanto ao seu desenvolvimento e consequências. Geralmente, a atenção dada à comunicação do risco é a que mais influencia no sucesso da avaliação do risco, bem como, na determinação e aceitação da estratégia de manejo do risco mais apropriada (MacDiarmid \& Pharo 2003). Assim, é muito importante que se estabeleça uma estratégia de comunicação com o objetivo de assegurar que todos os setores envolvidos participem e estejam informados do processo de tomada de decisões (OIE 2006).

\section{AR realizadas pelo SVO brasileiro}

Um compilado das AR e avaliações de risco realizadas no Brasil e publicadas, tanto as de Importação (ARI) como as de Risco Microbiológico (ARM) envolvendo animais aquáticos e animais terrestres e seus produtos, tendo ou não a participação do SVO brasileiro, está demonstrado no Quadro 1. Há estudos realizados no Brasil (Ferreira 2000; Nogueira et al 2011), que tratam de avaliação de consequências (difusão da doença e econômica) que não foram reportados no Quadro 1 por não se tratar de uma AR propriamente dita. Similarmente, estudos realizados especificamente com o intuito de definição de políticas sanitárias não foram relacionados pelas mesmas razões, embora sejam de reconhecida importância para a sanidade animal e suporte para tomada de decisão.

\section{1) Animais aquáticos}

No Brasil, quem responde pelo controle do trânsito nacional e interestadual de organismos aquáticos, incluindo a avaliação de risco de introdução de agentes infecciosos no território nacional por meio da importação de animais aquáticos e de suas formas de multiplicação, bem como pela importação de pescado e derivados é o MPA. Desde 2010 o MPA tem instituído procedimentos gerais para a realização de ARI de pescado e derivados e de animais aquáticos, células, órgãos e tecidos a fim de mensurar o impacto das importações na sanidade pesqueira e aquícola nacional (BRASIL 2010).

Em termos de institucionalização da técnica de AR no âmbito da defesa animal, o MPA é o mais avançado no Brasil. Além de produzir material específico sobre o assunto (Figueiredo et al. 2012c), até julho de 2013 já havia finalizado cinco ARI (sendo duas publicadas) e possuía outras 23 em andamento (MPA 2013). Foram finalizados processos de ARI de pescado e derivados de salmonídeos provenientes do Chile e da Noruega, de alevinos de tilápia do Nilo originários de Singapura (Figueiredo et al. 2012a), de sêmen de ostra Crassostrea gigas do Chile e de camarões para consumo humano originários da Argentina (Figueiredo et al. 2012b). Estão em andamento os processos de ARI de moluscos bivalves da subfamília Tridacninae para ornamentação, de camarões para consumo humano originários do Panamá e Equador, de filé de corvina originária do Chile, de filé de pangasius originário do Vietnã, de camarões para consumo humano originários da Índia, Portugal, Senegal e Noruega, de moluscos da classe Bivalvia e abalones para consumo humano originários do Chile e Peru, de filé de tilápia originário do Equador, de ovos férteis de truta arco-íris dos EUA para engorda, de mexilhões originários da Espanha para consumo humano e de filés de truta arco-íris originários do Peru (MPA 2013, Cunha et al. 2012).

As ARI são realizadas por um equipe de médicos veterinários e biólogos do MPA e revisadas por especialistas renomados na área. Ao final, as ARI servem de suporte para os envolvidos nas tomadas de decisão em aceitar ou não o pedido de importação, podendo solicitar medidas mitigadoras do risco, como por exemplo, na ARI de alevinos originários de Singapura destinados à multiplicação animal, onde o MPA concluiu que a importação é aceitável, desde que testes laboratoriais, aplicação de antibióticoterapia e quarentena fossem realizadas como medidas mitigatórias do risco avaliado. Tais AR do MPA são publicadas e podem ser debatidas por atores envolvidos, como fez a Associação Brasileira dos Criadores de Camarões (ABCC) a qual questionou a AR realizada pelo MPA (Maia \& Rocha 2013), solicitando a suspensão da importação de camarões da Argentina. Após julgamento inicial, a justiça brasileira não aceitou o pedido da $\mathrm{ABCC}$, tendo como argumento que o Brasil é signatário da OMC e que o MPA realizou a AR conforme preconizado e não impôs restrição a importação dos camarões originários da Argentina (CJF 2013). 


\section{2) Animais terrestres}

Em nível federal, o MAPA responde pela coordenação dos programas sanitários que norteiam a sanidade dos animais terrestres, assim como define o regramento quanto à inspeção de produtos de origem animal e o trânsito internacional de animais e seus produtos. A importação de animais terrestres e seus produtos derivados no Brasil se dá através de acordos sanitários internacionais firmados com países ou blocos econômicos, os quais consideram em um mesmo corpo de certificação as questões sanitárias especificas aplicáveis a cada caso. Estes acordo são precários, ou seja, passíveis de suspensão imediata no caso de alterações sanitárias nos países signatários. Ainda assim, pode ser considerado que não são realizadas ARI pelo MAPA, no sentido amplo do termo. Outros tipos de AR, como a Análise de Risco Microbiológica (ARM), que é uma ferramenta para promover a segurança dos alimentos de origem animal e vegetal (Reij \& Schothorst 2000, Cahill \& Jouve 2004, Schaffner 2008), também são pouco realizadas pelo SVO brasileiro (Mürmann et al 2011). Como consequência, há poucas ARM realizadas em nível nacional, conforme pode ser visualizado no Quadro 1. Em contrapartida, ARM tem sido cada vez mais utilizada por governos de países Europeus e nos Estados Unidos (USDA/ FSIS 1999, FAO/WHO 2002, FDA/FSIS 2003, USDA/FSIS
2005, EFSA 2010). Neste último, tanto o órgão responsável pela fiscalização e inspeção de produtos de origem animal (USDA/FSIS) e alimentos (DHHS/FDA) têm utilizado a ferramenta como método auxiliar no processo de decisão sobre questões de segurança dos alimentos, tanto domésticas como internacionais (Dennis et al. 2008).

Em adição, deve ser considerado que o processo de avaliação de risco é tradicionalmente utilizado na estruturação de instrumentos infra legais que normatizam os programas sanitários do MAPA (MAPA 1993, 1994, 1997, 2001a, 2001b, 2007, 2009, 2012). Os referidos instrumentos, fazendo uso do conceito de risco, são utilizados para regulamentar aspectos epidemiologicamente relevantes no controle e erradicação de enfermidades, de maneira aplicável ao macro cenário produtivo brasileiro. Tal estratégia tem sido aparentemente bem sucedida, nas doenças de controle oficial, considerando o progresso na condição sanitária dos rebanhos brasileiros, como no caso da febre aftosa e da peste suína clássica (MAPA 2010, 2013a, 2013b, 2013c, 2013d, 2013e, 2013f, 2013g, 2013h).

Em comparação com outros países, há poucas AR ligadas à área de sanidade de animais terrestres e microbiologia dos alimentos de origem animal realizadas no Brasil, sendo algumas sem a participação do SVO (Quadro 1).

Quadro 1. Análises e avaliações de risco publicadas com temas relacionados ao serviço veterinário oficial do Brasil

\begin{tabular}{lll}
\hline Ano & Classificação / Tipo & \multicolumn{1}{c}{ Foco } \\
\hline 2003 & $\begin{array}{l}\text { Avaliação de risco / } \\
\text { Qualitativa }\end{array}$ & $\begin{array}{l}\text { Avaliar a reintrodução do vírus } \\
\text { da febre aftosa no RS }\end{array}$ \\
2006 & $\begin{array}{l}\text { Avaliação de risco - ARI } \\
\text { / Quantitativa }\end{array}$ & $\begin{array}{l}\text { Avaliar a introdução do vírus } \\
\text { da febre aftosa através da im- } \\
\text { portação de produtos suínos } \\
\text { do Brasil }\end{array}$
\end{tabular}

2006 Análise de risco / Quali- Avaliar a presença de Encefatativa e Quantitativa lopatia Espongiforme Bovina no Brasil

2010 Avaliação de risco - ARI Avaliar a difusão do vírus da / Quantitativa

2011 Avaliação de risco / Avaliar áreas de risco elevado febre aftosa em produtos suínos exportados pela região Sul do Brasil Qualitativa para a ocorrência de raiva her- bívora na região do Vale do Rio Paraíba do Sul - SP

2011 Avaliação de risco - Avaliar a infecção por SalmoARM / Quantitativa nella em consumidores após ingestão de Linguiça frescal

2012 ARI / Qualitativa Camarões congelados originários da Argentina para consumo Humano

2012 ARI / Qualitativa Alevinos de Tilápia do Nilo originários de aquicultura

2012 Análise de risco / Qua- Avaliar a introdução do vírus litativa

2013 Avaliação de risco / Avaliação de risco / Avaliar a introdução do vírus
Qualitativa do Sul através da fronteira com o Paraguai

2013 Avaliação de risco - ARI Filés de Truta Arco-íris conge/ Qualitativa lados do Peru para consumo humano

\section{Não}

Sim; parcialmente

Sim; parcialmente

Não

Sim; parcialmente

Sim; parcialmente

Sim; parcialmente requisitos zoosanitários

Maior do que desprezível (muito baixo)

Sim; parcialmente

Diferentes cenários e regiões avaliadas e foram identificadas áreas/muncípios de maior risco de introdução do vírus

Não Insignificante para as doenças virais e parasitária (girodactilose)

$2,40 \times 10^{-8}$ de que uma carga de 100 ton de carne suína contaminada pelo vírus da febre aftosa seja exportada

Muito baixo, sendo que ss atuais medidas de mitigação de risco praticamente inviabilizam a amplificação do agente $6,03 \times 10^{-5}$ de que no volume total de lecionada esteja infectada

$81,8 \%$ dos focos de raiva foram adequadamente previstos pela avaliação de risco realizada.

$1,61 \times 10^{-3}$

Nenhum perigo identificado
Autores

Dutra 2003

que o maior risco de reintrodução do vírus está associado ao trânsito ilegal de animais

Salman et al 2006

MAPA 2006

Delphino 2010

Dias et al 2011

Mürmann et al 2011

Figueiredo et al 2012b

Figueiredo et al 2012a Corbellini et al 2012

Amaral 2013

Oliveira 2013 


\section{Limitações metodológicas na construção de uma AR no SVO brasileiro}

Os sistemas de vigilância em saúde animal desempenham um papel fundamental na disponibilização de dados com qualidade que poderão servir de subsídio para os estudos de AR (Zepeda et al 2001). No Brasil, há dificuldade dos sistemas de vigilância e monitoria em saúde animal de captar e registrar de forma tempestiva dados que venham a gerar informação de qualidade e conhecimento e, consequentemente, possam servir de base para construir uma AR. Tal problema não é exclusivo em nível nacional. Um exemplo dessa falta de dados pode ser exemplificado nas ARI realizadas pelo MPA, que na maioria das vezes opta por avaliações qualitativas, pois nas avaliações quantitativas há uma demanda por dados muito detalhados e precisos no país de origem, como por exemplo distribuição e prevalência dos perigos biológicos elencados, o que reduz sua aplicabilidade devido à escassez e limitação de dados e conhecimento acerca do cenário de saúde dos animais aquáticos (Figueiredo et al. 2012a).

A falta de capacitação e, consequentemente, de pessoal preparado dentro do SVO é outro gargalo da realização de AR. Centros colaboradores da OIE realizam cursos de epidemiologia e análise de risco de curta duração a fim de capacitar profissionais do SVO. Além desses, outras instituições no mundo promovem cursos de análise de risco a fim de preparar profissionais nessa área (Zepeda et al. 2005), como é o caso do IICAA na América do Sul. No Brasil, assim como em outros países em desenvolvimento, há uma dificuldade na formação de analistas de risco dentro do SVO (Zepeda et al. 2005) e, como consequência há carência de pessoal com essa expertise no SVO.

A segmentação das AR também pode ser apontada como um problema. Por exemplo, nas AR realizadas pelo MPA somente são avaliados os potenciais perigos para a saúde dos animais aquáticos, uma vez que a avaliação de potenciais perigos à saúde humana e ao meio ambiente não é de responsabilidade legal do MPA (Figueiredo 2012b). 0 ideal seria a criação de grupos interministeriais que pudessem trabalhar as AR como um todo, visando todos os potenciais perigos inerentes a importação de um animal ou produto, a fim de ter resultados mais eficientes para a sociedade. Uma alternativa seria criar uma única unidade a qual seria a responsável por coordenar todas as AR realizadas dentro do escopo do acordo SPS evitando a sobreposição de trabalho (Neeliah \& Goburdhun 2010, Figueiredo \& Miranda 2011). Na Europa, o órgão envolvido na coordenação e condução de avaliações de risco é o EFSA (European Food safety Authority). O EFSA é um órgão independente que possui diversos comitês científicos que colaboram nas decisões sobre as questões ligadas a segurança dos alimentos, saúde animal dentre outras, sendo responsável pela condução da avaliação e comunicação de riscos que são requeridas pela Comissão Europeia ou por países membros (EFSA 2103). Os avaliadores de risco são normalmente membros de comitês científicos ou profissionais ligados a alguma divisão específica de avaliação de risco dentro dos serviços de vigilância e saúde pública ou órgãos de inspeção federal, a exemplo do que ocorre na
BfR (Bundesinstitut für Risikobewertung) na Alemanha, FSIS e FDA nos EUA.

\section{DISCUSSÃO E CONCLUSÕES}

A AR é uma ferramenta que pode auxiliar cientificamente o SVO na tomada de decisão, tanto para autorizar, de forma segura, o ingresso de animais e produtos de origem animal de outros países, como para avaliar seu próprio sistema de vigilância e monitoria em busca de pontos com maiores vulnerabilidades. Adicionalmente, a AR agrega transparência ao processo por permitir a visibilidade de critérios e a padronização de procedimento. Tal característica é especialmente interessante no caso do comercio internacional, o qual tem sido objeto de crescente regulamentação por organismos normatizadores visando reduzir a aplicação de barreiras não tarifárias ao comércio.

A metodologia a ser seguida da construção de uma AR, apesar de possuir algumas limitações metodológicas, é clara, objetiva, sistemática e transparente, podendo ser utilizada de diversas formas pelo SVO. No Brasil, ainda são poucas as AR realizadas e publicadas, mas mostram uma evolução nos últimos três anos (Quadro 1). 0 cenário nacional começou a ser modificado pelo MPA, o qual têm diversas ARI em andamento, além de cinco concluídas desde 2012, no que tange os animais aquáticos e seus produtos. Há uma equipe qualificada e definida que coordena a realização e divulgação desses estudos. Em contraste a isso, na área dos animais terrestres há poucos trabalhos realizados no MAPA, assim como nos órgãos estaduais de defesa sanitária animal. A maioria dos estudos realizados no Brasil na área de AR no âmbito de saúde dos animais terrestres foi desenvolvida por pesquisadores de universidades, em conjunto com o SVO (Quadro 1). A não realização de ARI de importação pelo MAPA, ao contrário do que realiza o MPA, pode ser um dos motivos que levem o SVO brasileiro, na parte de animais terrestres, a ainda ter um número pequeno de AR realizadas.

Apesar disso, assim como ocorre no MPA, algumas AR, em animais terrestres estão em andamento no Brasil. No Rio Grande do Sul (RS), em 2012, após a formatação de um acordo de cooperação técnica entre o SVO e a universidade (Santos et al. 2012), iniciaram-se duas AR, sendo uma para avaliar o risco da população de suínos asselvajados ter contato com a população de suínos comerciais no Estado (Medeiros et al. 2012) e outra que visa avaliar o risco da entrada do vírus da febre aftosa no RS (Santos et al. 2013a). Tais estudos poderão servir de base para assessorar os gestores do SVO gaúcho quanto à implantação de novas medidas de mitigação de risco, caso a análise evidencie a existência de vulnerabilidades que atualmente não são contempladas pelo sistema de defesa. Nestes dois casos, não se trata de análise de risco de importação ou microbiológica, os dois tipos de AR mais comumente desenvolvidos no âmbito governamental, mas exemplifica o potencial da ferramenta no auxílio para a tomada de decisão em diferentes situações (Dewdney et al. 1991, McElvaine et al. 1993, Donaldson et al. 2001, Schijven et al. 2005, Ortiz-Pelaez et al. 2006, Acevedo et al. 2007, Boklund et al. 2008, Martinez-Lopez et al. 2008, 2009, Ge et al. 2010, Lane et 
al. 2010, Napp et al. 2010, Frossling et al. 2012, Havas et al. 2012).

Apesar de todo o benefício que uma AR pode trazer, ela ainda possui alguns importantes gargalos que dificultam seu uso disseminado pelo SVO brasileiro. A falta de dados e de profissional especializado na área são dificuldades encontradas rotineiramente. Sabendo-se da importância da AR para balizar o comércio pecuário mundial e do papel que as exportações dos produtos agropecuários possuem no superávit da balança comercial brasileira, resta indubitável que tanto o governo quanto as cadeias produtivas da pecuária nacional deveriam investir na formação de profissionais capacitados no SVO brasileiro capazes de atender as demandas internas e realizar AR de interesse nacional para os animais terrestres. No que se refere ao comercio internacional, tal qualificação permitiria às autoridades brasileiras manterem linhas de diálogos técnicos com seus pares de países parceiros comerciais, utilizando-se do suporte conferido pelo Acordo SPS e contornando e modelando subjetividades intrínsecas aos modelos de AR. Já em âmbito nacional, a AR permitiria uma abordagem técnico-gerencial aos programas sanitários vigentes, bem como a identificação de pontos críticos de controle e novos programas a serem desenvolvidos. A estruturação de unidades de AR, neste caso, deve buscar uma dimensão adequada às necessidades nacionais, considerando as demandas internas, dos diversos programas sanitários vigentes, e a complexidade de seus contextos de implantação relacionados à extensão territorial do país e suas idiossincrasias culturais. Além disso, especialistas poderiam ser convidados para contribuir em suas áreas de expertise, dentro da ideia de tratar cada AR como um projeto específico, como preconizado pela OIE (2006) e como ocorre no MPA (Figueiredo et al. 2012a, 2012b). Algumas AR construídas no Brasil seguiram um modelo de parceria entre a universidade e o SVO (Dias et al. 2011, Corbellini et al. 2012, Amaral 2013) o que deveria ser estimulado. 0 modelo adotado nesses casos, de buscar uma aproximação junto à academia e formar parcerias na construção de AR gera bons resultados. As autoridades dos SVO deveriam estabelecer um trabalho em conjunto com a comunidade científica (e vice-e-versa). Essa ligação poderia ser estabelecida através de epidemiologistas trabalhando nos serviços veterinários (Zepeda et al. 2005).

A AR é um processo governamental, desenvolvido para responder às questões formuladas pelos responsáveis pela gestão dos riscos identificados (Sant'ana \& Franco 2009). Os desafios para o desenvolvimento de AR pelo SVO brasileiro ainda são grandes, destacando-se aqueles relacionados à falta de dados e de pessoal capacitado. Alternativas como a criação de um sistema web nacional de monitoria e vigilância e a formatação de parcerias com universidades e instituições de pesquisas (Corbellini et al. 2012, Hasler et al. 2012), no entanto, tornam possível evoluir na produção de dados e formação e capacitação de profissionais nessa área, objetivando que, em um futuro próximo, o SVO brasileiro possa realizar diversas AR de seu interesse, visando dar suporte aos gestores na implantação de políticas públicas na área da saúde animal, além de proteger a sanidade dos rebanhos nacionais.
Agradecimentos.- Ao Fiscal Estadual Agropecuário Fernando Henrique Sautter Groff pela análise, discussão e melhorias apontadas na construção desse artigo. Ao Conselho Nacional de Desenvolvimento Científico e Tecnológico (CNPq) pelo suporte financeiro realizado pelo Edital CNPq/ MAPA/SDA № 64/2008 processo 578781/2008-5.

\section{REFERÊNCIAS}

Acevedo P., Vicente J., Hofle U., Cassinello J., Ruiz-Fons F. \& Gortazar C. 2007. Estimation of european wild boar relative abundance and aggregation: a novel method in epidemiological risk assessment. Epidemiol. Infect. 135(3):519-527.

Almeida E.P.D. 2005. Técnicas de análise de risco aplicadas à planejamento e programação de projetos da construção civil. Dissertação de Mestrado em Engenharia Civil, Universidade Federal Fluminense, Niteroi. 163p.

Amaral T.B. 2013. Risk assessment of Foot and Mouth Disease in the border between Brazil and Paraguay: a geographical approach. Tese de Doutorado, Université Laval, Quebec, Canada. 154p.

AQIS 1999. Import risk analysis report on the importation of bovine semen and embryos from Argentina and Brazil into Australia. Disponível em <http://www.daff.gov.au/_data/assets/pdf_file/0014/14324/00-003a.pdf> Acesso em 11 jan. 2014.

Armstrong T.W. \& Haas C.N. 2007. A quantitative microbial risk assessment model for Legionnaires' disease: animal model selection and dose-response modeling. Risk Anal. 27(6):1581-1596.

Bier V.M. \& Mosleh A. 1990. The analysis of accident precursors and near misses: implications for risk assessment and risk management. Reliab. Eng. Syst. Safe. 27(1):91-101.

Boklund A., Goldbach S.G., Uttenthal A. \& Alban L. 2008. Simulating the spread of classical swine fever virus between a hypothetical wild-boar population and domestic pig herds in Denmark. Prev. Vet. Med. 85(3/4):187-206.

Brasil 2010. Instrução Normativa do Ministério da Pesca e Aquicultura N. 14 de 9 de dezembro de 2010. Diário Oficial da União de 10 dez. 2010, p.71.

Brückner G.K. 2009. The role of the World Organisation for Animal Health (OIE) to facilitate the international trade in animals and animal products. Onderstepoort J. Vet. 76:141-146.

CAC 1999. Principles and guidelines for the conduct of microbiological risk assessment. CAC/GL-30. Disponível em <http://www.codexalimentarius.org/standards/list-of-standards/en/?no_cache=1> Acesso em 16 out. 2013.

CAC 2007. Working Principles for Risk Analysis for Food Safety for Application by Governments. CAC/GL-62. Disponível em <http://www. codexalimentarius.org/standards/list-of-standards/en/?no_cache=1> Acesso em 16 out. 2013.

CAC 2011. Procedural Manual. 21 ed. Disponível em <ftp://ftp.fao.org/ codex/Publications/ProcManuals/Manual_21e.pdf> Acesso em 16 out. 2013.

Cahill S.M. \& Jouve J.R. 2004. Microbiological risk assessment in developing countries. J. Food Protect. 67(9):2016-2023.

Campbell M.L. 2008. Organism impact assessment: risk analysis for post-incursion management. Ices J. Mar. Sci. 65(5):795-804.

Carr V. \& Tah J.H.M. 2001. A fuzzy approach to construction project risk assessment and analysis: construction project risk management system. Adv. Eng. Softw. 32(10/11):847-857.

CJF 2013. Disponível em <http://www.cjf.jus.br/cjf/outras-noticias/2013/junho/mantida-autorizacao-do-ministerio-da-pesca-para-importacao-de-camaroes-argentinos> Acesso em 20 dez. 2013.

Cohen N.E., Van Asseldolnk M.A.P.M. \& Stassen E.N. 2007. Social-ethical issues concerning the control strategy of animal diseases in the European Union: a survey. Agric. Human Values 24:499-510.

Corbellini L.G., Marks F. \& Todeschini B. 2010. Panorama da influenza A pandêmica H1N1 em suínos: situação atual e avaliação dos riscos. Acta Scient.Vet. 38:46-52.

Corbellini L.G., Pellegrini D.C., Dias R.A., Reckziegel A., Todeschini B. \& 
Bencke G.A. 2012. Risk assessment of the introduction of H5N1 highly pathogenic avian influenza as a tool to be applied in prevention strategy plan. Transbound Emerg. Dis. 59(2):106-116.

Covello V.T. \& Merkhoher M.W. 1993. Risk Assessment Methods: Approaches for Assessing Health and Environmental Risks. Plenum Press, New York. 319p.

Cox Jr L.A. 2008. What's wrong with risk matrices? Risk Anal. 28(2):497511.

Cunha E.A.P., Delphino M.K.V.C., Blume L.R., Oliveira P.H.S. \& Figueiredo H.C.P. 2012. Serviço veterinário oficial e análise de risco de importação em sanidade aquícola e Pesqueira. Acta Scient. Vet. 40(Supl.2):107.

Delphino M.K.V.C. 2010. Avaliação do risco de difusão do vírus da febre aftosa em produtos suínos exportados pela região sul do Brasil. Dissertação de Mestrado, Universidade de Brasília, Brasília. 73p.

Dennis S.B., Kause J., Losikoff M., Engeljohn D.L. \& Buchanan R.L. 2008. Using risk Analysis for microbial food safety regulatory decision making, p.137-175. In: Schaffer D. (Ed.), Microbial Risk Analysis of Foods. ASM Press, Washington, DC.

Dewdney J.M., Maes L., Raynaud J.P., Blanc F., Scheid J.P., Jackson T., Lens S. \& Verschueren C. 1991. Risk assessment of antibiotic residues of beta-lactams and macrolides in food products with regard to their immuno-allergic potential. Food Chem. Toxicol. 29(7):477-483.

Dias R.A., Nogueira Filho V.S., Goulart C.S., Telles I.C.O., Marques G.H.F., Ferreira F., Amaku M. \& Ferreira Neto J.S. 2011. Modelo de risco para circulação do vírus da raiva em herbívoros no Estado de São Paulo, Brasil. Revta Panam. Salud Publica 30(4):370-376.

Dohoo I., Martin W. \& Stryhn H. 2010. Veterinary Epidemiologic Research. Review Inc., Canada. 865p.

Donaldson A.I., Alexandersen S., Sorensen J.H. \& Mikkelsen T. 2001. Relative risks of the uncontrollable (airborne) spread of FMD by different species. Vet. Rec. 148(19):602-604.

Dufour B., Plee L., Moutou F., Boisseleau D., Chartier C., Durand B., Ganiere J.P., Guillotin J., Lancelot R., Saegerman C., Thebault A., Hattenberger A.M. \& Toma B. 2011. A qualitative risk assessment methodology for scientific expert panels. Rev. Sci. Tech. 30(3):673-681.

Dutra M.G.B. 2003. Evaluación cualitativa del riesgo de reintroducción de la fiebre aftosa en el estado de Rio Grande do Sul. Tese de Doutorado em Saúde animal. Faculdade de Veterinária, Universidade de Murcia, Múrcia, España. 246p.

EFSA 2010. Scientific opinion on a quantitative microbiological risk assessment of Salmonella in slaughter and breeder pigs. EFSA Journal 8(4). 80p. Disponível em <http://www.efsa.europa.eu/en/efsajournal/ pub/1547.htm> Acesso em 7 out. 2013.

Evans B. 2006. The social and political impact of animal diseases. Vet. Ital. 42(4):399-406.

Everett W.D. 1981. Risk of coronary heart disease-risk analysis in the clinical practice of aerospace medicine using a programmable calculator. Aviat Space Environ. Med. 52(9):561-563.

FAO/WHO 2002. Risk assessments of Salmonella in eggs and broiler chickens. Microbiological Risk Assessment Series no.2. Joint FAO/WHO activities on microbiological risk assessment. Food and Agriculture Organization of the United Nations, Rome, Italy.

FDA/FSIS 2003. Quantitative assessment of the relative risk to public health from foodborne Listeria monocytogenes among selected categories of read-to-eat foods. Disponível em <http://www.fda.gov/downloads/ food/scienceresearch/researchareas/riskassessmentsafetyassessment/ucm197330.pdf> Acesso em 16 out. 2013.

Ferreira F. 2000. Dinâmica especial da Febre Aftosa em bovinos: um modelo matemático. Tese de Doutorado em Epidemiologia, Faculdade de Saúde Pública, Universidade de São Paulo, São Paulo/SP. 82p.

Figueiredo A.V.A \& Miranda M.S. 2011. Análise de risco aplicada aos alimentos no Brasil: perspectivas e desafios. Ciênc. Saude Coletiva 16 (4):2251-2262.

Figueiredo H.C.P., Cunha E.A.P., Delphino M.K.V.C., Blume L.R., Machado D.P. \& Oliveira P.H.S. 2012a. Análise de Risco de Importação: alevinos da espécie Orechromis niloticus (Tilápia do Nilo) originários de aquicultura de Singapura, destinados à multiplicação animal. Ministério da Pesca e Aquicultura, Brasília. 135p.

Figueiredo H.C.P., Cunha E.A.P., Delphino M.K.V.C. \& Blume L.R. 2012b. Análise de Risco de Importação: camarões congelados da espécie Pleoticus muelleri originários de pesca extrativa da Argentina, destinados ao consumo humano. Ministério da Pesca e Aquicultura, Brasília. 46p.

Figueiredo H.C.P., Cunha E.A.P., Delphino M.K.V.C., Blume L.R., Machado D.P. \& Oliveira P.H.S. 2012c. Análise de Risco de Importação: metodologia básica. Ministério da Pesca e Aquicultura, Brasília. 34p.

Frossling J., Ohlson A., Bjorkman C., Hakansson N. \& Noremark M. 2012. Application of network analysis parameters in risk-based surveillance: examples based on cattle trade data and bovine infections in Sweden. Prev. Vet. Med. 105(3):202-208.

Ge L., Mourits M.C., Kristensen A.R. \& Huirne R.B. 2010. A modelling approach to support dynamic decision-making in the control of FMD epidemics. Prev. Vet. Med. 95(3/4):167-174.

Hasler B., Howe K.S., Hauser R. \& Stark K.D. 2012. A qualitative approach to measure the effectiveness of active avian influenza virus surveillance with respect to its cost: a case study from Switzerland. Prev. Vet. Med. 105(3):209-222.

Hauser R., Breidenbach E., Thür B., Griot C., Engels M. \& Stärk K. 2004. Import risk analysis in animal disease control. Berl. Münch. Tierärztl. Wochenschr. 117(5/6):188-192.

Havas K.A., Ramishvili M., Navdarashvili A., Imnadze P. \& Salman M. 2012. The human-animal interface of domestic livestock management and production and its relationship to brucellosis in the country of Georgia 2010: a rapid assessment analysis. Prev. Vet. Med. 105(1/2):10-16.

Lane C., Tameru B., Nganwa D., Habtemariam T., Asseged B., Robnett V. \& Wilson S. 2010. A quantitative risk assessment for the likelihood of introduction of highly pathogenic avian influenza virus strain H5N1 into U.S. hunter retriever dogs. Avian Dis. 54(Suppl.1):699-706.

Leanes L.F., Abbiati N.N., Pereyra A.M. \& Maizon D.O. 2011. Risk evaluation of nonvaccinated, weaned calves transported through areas under systematic foot and mouth disease (FMD) vaccination. Prev. Vet. Med. 98(2/3):133-141.

MacDiarmid S.C. 1993. Risk analysis and the importation of animals and animal products. Rev. Sci. Tech. 12(4):1093-1107.

MacDiarmid S.C. \& Pharo H. 2003. Risk analysis: assessment, management and communication. Rev. Sci. Tech. 22(2):397-408.

Maia E.P. \& Rocha I.P. Contestação da ABCC ao documento analise de risco de importação (ARI): Camarões congelados da espécie Pleoticus muelleri da Argentina, destinados ao consumo humano, realizada pela CGSAP/MPA com solicitação de sua definitiva revogação. Disponível em <http://abccam.com.br/site/documentos-relacionados-ao-pedido-administrativo-de-anulacao-da-ari/> Acesso em 12 dez. 2013.

MAPA 1993. Portaria no 121 de 30 de março de 1993. Disponível em <http://sistemasweb.agricultura.gov.br/sislegis/action/detalhaAto.do ?method=consultarLegislacaoFederal $>$ Acesso em 27 jan. 2014.

MAPA 1994. Portaria no 194 de 29 de novembro de 1994. Disponível em <http://sistemasweb.agricultura.gov.br/sislegis/action/detalhaAto.do ?method=consultarLegislacaoFederal $>$ Acesso em 27 jan. 2014.

MAPA 1997. Portaria no 050 de 19 de maio de 1997. Disponível em $<$ http://sistemasweb.agricultura.gov.br/sislegis/action/detalhaAto.do ?method=consultarLegislacaoFederal $>$ Acesso em 27 jan. 2014.

MAPA 2001a. Instrução Normativa no 01 de 4 de janeiro de 2001. Disponível em <http://sistemasweb.agricultura.gov.br/sislegis/action/ detalhaAto.do?method=consultarLegislacaoFederal $>$ Acesso em 27 jan. 2014.

MAPA 2001b. Instrução Normativa no 35 de 010 de Julho de 2001. Disponível em <http://sistemasweb.agricultura.gov.br/sislegis/action/ detalhaAto.do?method=consultarLegislacaoFederal $>$ Acesso em 27 jan. 2014.

MAPA 2006. Análise de Risco para Encefalopatia Espongiforme Bovina no Brasil. Ministério da Agricultura, Pecuária e Abastecimento, Brasília. 41p.

MAPA 2007. Instrução Normativa no 044 de 2 de outubro de 2007. Dis- 
ponível em <http://sistemasweb.agricultura.gov.br/sislegis/action/ detalhaAto.do?method=consultarLegislacaoFederal $>$ Acesso em 27 jan. 2014.

MAPA 2009. Norma Interna no 05 de 21 de agosto de 2009. Disponível em <http://www.iagro.ms.gov.br/controle/ShowFile.php?id=45423> Acesso em 27 jan. 2014.

MAPA 2010. Instrução Normativa no 06 de 22 de fevereiro de 2010. Disponível em <http://sistemasweb.agricultura.gov.br/sislegis/action/ detalhaAto.do?method=consultarLegislacaoFederal $>$ Acesso em 27 jan. 2014.

MAPA 2012. Instrução Normativa no 036 de 6 de dezembro de 2012. Disponível em <http://sistemasweb.agricultura.gov.br/sislegis/action/ detalhaAto.do?method=consultarLegislacaoFederal> Acesso em 27 jan. 2014.

MAPA 2013a. Instrução Normativa no 033 de 19 de agosto de 2013. Disponível em <http://sistemasweb.agricultura.gov.br/sislegis/action/ detalhaAto.do?method=consultarLegislacaoFederal $>$ Acesso em 27 jan. 2014.

MAPA 2013b. Instrução Normativa no 034 de 5 de setembro de 2013. Disponível em <http://sistemasweb.agricultura.gov.br/sislegis/action/ detalhaAto.do?method=consultarLegislacaoFederal $>$ Acesso em 27 jan. 2014.

MAPA 2013c. Instrução Normativa no 035 de 6 de setembro de 2013. Disponível em <http://sistemasweb.agricultura.gov.br/sislegis/action/ detalhaAto.do?method=consultarLegislacaoFederal $>$ Acesso em 27 jan. 2014.

MAPA 2013d. Instrução Normativa no 036 de 6 de setembro de 2013. Disponível em <http://sistemasweb.agricultura.gov.br/sislegis/action/ detalhaAto.do?method=consultarLegislacaoFederal $>$ Acesso em 27 jan. 2014.

MAPA 2013e. Instrução Normativa no 037 de 10 de setembro de 2013. Disponível em <http://sistemasweb.agricultura.gov.br/sislegis/action/ detalhaAto.do?method=consultarLegislacaoFederal $>$ Acesso em 27 jan. 2014.

MAPA 2013f. Instrução Normativa no 038 de 10 de setembro de 2013. Disponível em <http://sistemasweb.agricultura.gov.br/sislegis/action/ detalhaAto.do?method=consultarLegislacaoFederal $>$ Acesso em 27 jan. 2014.

MAPA 2013g. Instrução Normativa no 039 de 10 de setembro de 2013. Disponível em <http://sistemasweb.agricultura.gov.br/sislegis/action/ detalhaAto.do?method=consultarLegislacaoFederal $>$ Acesso em 27 jan. 2014.

MAPA 2013h. Instrução Normativa no 040 de 10 de setembro de 2013. Disponível em <http://sistemasweb.agricultura.gov.br/sislegis/action/ detalhaAto.do?method=consultarLegislacaoFederal $>$ Acesso em 27 jan. 2014.

Marabelli R. 2003. The role of official Veterinary Services in dealing with new social challenges: animal health and protection, food safety, and the environment. Rev. Sci. Tech. 22(2):363-371.

Markowski A.S. \& Mannan M.S. 2008. Fuzzy risk matrix. J. Hazard Mater. 159:152-157.

Martinez-Lopez B., Perez A.M., De la Torre A. \& Rodriguez J.M. 2008. Quantitative risk assessment of foot-and-mouth disease introduction into Spain via importation of live animals. Prev. Vet. Med. 86(1/2):43-56.

Martinez-Lopez B., Perez A.M. \& Sanchez-Vizcaino J.M. 2009. A stochastic model to quantify the risk of introduction of classical swine fever virus through import of domestic and wild boars. Epidemiol. Infect. 137(10):1505-1515.

McElvaine M.D., McDowell R.M., Fite R.W. \& Miller L. 1993. An assessment of the risk of foreign animal disease introduction into the United States of America through garbage from Alaskan cruise ships. Rev. Sci. Tech. 12(4):1165-1174.

Medeiros A.A.R., Santos D.V. \& Corbelini L.G. 2012. Análise de risco da Exposição dos Javalis asselvajados à população de suínos comerciais do Rio Grande do Sul. 2012. Anais III Congresso Sul Brasileiro de Avicultura, Suinocultura e Laticínios, Bento Gonçalves, RS.
Miller L., McElvaine M.D., McDowell R.M. \& Ahl A.S. 1993. Developing a quantitative risk assessment process. Rev. Sci. Tech. 12(4):1153-1164.

Moutou F., Dufour B. \& Ivanov Y. 2001. A qualitative assessment of the risk of introducing foot and mouth disease into Russia and Europe from Georgia, Armenia and Azerbaijan. Rev. Sci. Tech. 20(3):723-730.

MPA 2013. Disponível em<http://www.mpa.gov.br/images/Docs/ Monitoramento_e_Controle/IMPORTACAO/Quadro\%20de\%20Processos\%20de\%20ARI\%20-\%2017.07.2013.pdf> Acesso em 26 nov. 2013.

Mur L., Martinez-Lopez B., Martinez-Aviles M., Costard S., Wieland B., Pfeiffer D.U. \& Sanchez-Vizcaino J.M. 2012. Quantitative risk assessment for the introduction of African swine fever virus into the European Union by legal import of live pigs. Transbound Emerg. Dis. 59(2):134-144.

Murmann L., Corbellini L.G., Collor A.A. \& Cardos M. 2011. Quantitative risk assessment for human salmonellosis through the consumption of pork sausage in Porto Alegre, Brazil. J. Food Prot. 74(4):553-558.

Murray N., MacDiarmid S.C., Wooldridge M., Gummow B., Morley R.S., Weber S.E., Giovannini A. \& Wilson D. 2004. Handbook on Import Risk Analysis for Animals and Animal Products: introduction and qualitative risk analysis. OIE, Paris.

Napp S., Casas M., Moset S., Paramio J.L. \& Casal J. 2010. Quantitative risk assessment model of canine rabies introduction: application to the risk to the European Union from Morocco. Epidemiol. Infect. 138(11):15691580.

Nauta M.J. 2000. Separation of uncertainty and variability in quantitative microbial risk assessment models. Int. J. Food Microbiol. 57:9-18.

Neeliah S.A. \& Goburdhun D. 2010. Complying with the clauses of the SPS agreement: Case of developing country. Food Control 21:902-911.

Ni H., Chen A. \& Chen N. 2010. Some extensions on risk matrix approach. Safety Sci. 48:1269-1278.

Nogueira J.M., Doliveira C.F.D. \& Burer S.P. 2011. Relatório Final: análise custo benefício de estratégias de controle da febre aftosa no Paraná. FAEP, Curitiba. 154p.

OIE 2006. Análisis de Riesgo: guia práctica, World Animal Health Organization, Paris. 60p.

OIE 2012a. Aquatic Animal Health Code (the Aquatic Code). Paris, OIE. Disponível em <http://www.oie.int/international-standard-setting/ aquatic-code/access-online/> Acesso em 29 jan. 2013.

OIE 2012b. Terrestrial Animal Health Code (Terrestrial Code). $21^{\text {st }}$ ed. Paris. 739p.

OIE 2013a. Disponível em <http://www.oie.int/wahis_2/public/wahid. php/Wahidhome/Home> Acesso em 29 abr. 2013.

OIE 2013b. Disponível em <http://www.oie.int/about-us/> Acesso em 29 abr. 2013.

Oliveira M.L.B.R. 2013. Avaliação de risco para a importação de filés de truta arco-íris (Oncorhynchus mykiss), congelados, originários de aquicultura do Peru, destinados ao consumo humano. Monografia de Conclusão de Curso. Universidade de Brasília, Brasília. 56p.

Ortiz-Pelaez A., Pfeiffer D.U., Soares-Magalhaes R.J. \& Guitian F.J. 2006. Use of social network analysis to characterize the pattern of animal movements in the initial phases of the 2001 foot and mouth disease (FMD) epidemic in the UK. Prev. Vet. Med. 76(1/2):40-55.

Palmer S., Brown D. \& Morgan D. 2005. Early qualitative risk assessment of the emerging zoonotic potential of animal diseases. BMJ 331(7527):1256-1260.

Paton D.J., Sinclair M. \& Rodriguez R. 2010. Qualitative assessment of the commodity risk for spread of foot-and-mouth disease associated with international trade in deboned beef. Transbound Emerg. Dis. 57(3):115134.

Pintelon L. 1994. Risk: analysis, assessment and management. Ansell J. \& Wharton F. Eur. J. Operational Res. 78(1):142-142.

Pouillot R., Garin B., Ravaonindrina N., Diop K., Ratsitorahina M., Ramanantsoa D. \& Rocourt J. 2012. A risk assessment of Campylobacteriosis and Salmonellosis linked to chicken meals prepared in households in Dakar, Senegal. Risk Anal. 32(10):1798-1819. 
Reij M.W. \& Schothorst M.V. 2000. Critical notes on microbiological risk assessment of food. Braz. J. Microbiol. 31:01-08.

Salman M.D., Gonçalves V.S.P. \& Wongsathapornchai K. 2006. Risco de introdução da febre aftosa através da importação de produtos suínos do Brasil: Avaliação de riscos. Disponível em <http://file.aviculturaindustrial.com.br/Material/Tecnico/abipecs_aftosa.pdf> Acesso em $22 \mathrm{dez}$. 2013.

Sanchez-Vizcaino F., Perez A., Lainez M. \& Sanchez-Vizcaino J.M. 2010a. A quantitative assessment of the risk for highly pathogenic avian influenza introduction into Spain via legal trade of live poultry. Risk Anal. 30(5):798-807.

Sanchez-Vizcaino F., Perez A., Lainez M. \& Sanchez-Vizcaino J.M. 2010b. Quantification of the risk for introduction of virulent Newcastle disease virus into Spain through legal trade of live poultry from European Union countries. Avian Pathol. 39(6):459-465.

Sant'Ana A.S. \& Franco B.D.G.M. 2009. Avaliação quantitativa de risco microbiológico em alimentos: conceitos, sistemática e aplicações. Braz. J. Food Technol. 12(4):226-276.

Santos D.V., Vidor A.C.M. \& Corbellini L.G. 2012. 0 fortalecimento do serviço veterinário oficial gaúcho mediante acordo de cooperação técnica com a Universidade Federal do Rio Grande do Sul. Anais III Congresso Sul Brasileiro de Avicultura, Suinocultura e Laticíneos, Bento Gonçalves, RS.

Santos D.V., Groff F.H.S., Todeschini B., Canal C.W. \& Corbellini L.G. 2013a. Análise de risco da introdução do vírus da Febre Aftosa no Estado do Rio Grande do Sul. Biológico, São Paulo, 75:31-31.

Santos D.V., Correa A.M.R., Medeiros A.A.R., Kohek Junior I., Todeschini B. \& Corbellini L.G. 2013b. A importância da aproximação entre o Serviço Veterinário Oficial e a Universidade. Anais IV Conferência Nacional sobre Defesa Agropecuária, Belém, PA.

Schaffner D.W. 2008. Microbial Risk Analysis of Foods. ASM Press, Washington, DC.

Schijven J., Rijs G.B. \& Roda Husman A.M. 2005. Quantitative risk assessment of FMD virus transmission via water. Risk Anal. 25(1):13-21.

Silverglade B.A. 2000. The WTO Agreement on Sanitary and Phytosanitary Measures: weakening food safety regulations to facilitate trade? Food Drug Law J. 55:517-524.

Thiermann A.B. 2005. Globalization, international trade and animal health: the new roles of OIE. Prev. Vet. Med. 67:101-108.

Uhlenhopp E.K. 2002. Bio-terrorism and the need for veterinary services in a global society: risk analysis, hazard analysis and critical control points (HACCP). Livest. J. Vet. Med. Educ. 29(4):212-215.

Urbina-Amaris M.E. 2003. The role of a specialised risk analysis group in the Veterinary Services of a developing country. Rev. Sci. Tech. 22(2):587-595.

USDA/FSIS 1999. Performance Standards for the Production of Certain Meat and Poultry Products. Disponível em <http://www.fsis.usda.gov/ wps/portal/frame-redirect?url=http://www.fsis.usda.gov/OPPDE/ rdad/FRPubs/95-033F.htm> Acesso em 8 out. 2013.

USDA/FSIS 2005. Risk Assessment of the Impact of Lethality Standards on Salmonellosis fron Ready-to-Eat Meat and Poutry Products. Disponível em <http://www.fsis.usda.gov/wps/wcm/connect/ace90cc5-2be2-4fa3-9ed5-2b186cae976c/Salm_RTE_Risk_Assess_ExecSumm_ Sep2005.pdf?MOD=AJPERES> Acesso em 16 out. 2013.

Vallat B. \& Wilson D.W. 2003. The obligations of Member Countries of the OIE (World Organisation for Animal Health) in the Organisation of Veterinary Services. Rev. Sci. Tech. 22(2):547-559.

WHO 1995. Agreement on the application of sanitary and phytosanitary measures. In The results of the Uruguay Round of Multilateral Trade Negotiations: the legal texts. World Trade Organization, Geneva.

WHO 2013. Disponível em <http://web.worldbank.org/WBSITE/EXTERNAL/NEWS/0,,contentMDK:20954941 pagePK:64257043 piPK:437 376 theSitePK:4607,00.html> Acesso em 29 abr. 2013.

WHO/FAO 2005. Understanding the Codex Alimentarius. Disponível em <http://www.fao.org/docrep/008/y7867e/y7867e00.HTM> Acesso em 16 out. 2013.

Willeberg P., Nielsen L.R. \& Salman M. 2012. Designing and evaluating risk-based surveillance systems: Potential unwarranted effects of applying adjusted risk estimates. Prev. Vet. Med. 105(3):185-194.

Yu P., Habtemariam T., Wilson S., Oryang D., Nganwa D., Obasa M. \& Robnett V. 1997. A risk-assessment model for foot and mouth disease (FMD) virus introduction through deboned beef importation. Prev. Vet. Med. 30(1):49-59.

Zepeda C., Salman M. \& Ruppanner R. 2001. International trade, animal health and veterinary epidemiology: challenges and opportunities. Prev. Vet. Med. 48:261-271.

Zepeda C., Salman M., Thiermann A., Kellar J., Rojas H. \& Willeberg P. 2005. The role of veterinary epidemiology and veterinary services incompling with the Word Trade Organization SPS agreement. Prev. Vet. Med. 67:125-140. 